\title{
ADUBAÇÃO NITROGENADA DO FEIJOEIRO, EM PLANTIO E COBERTURA, EM PLANTIO DIRETO E CONVENCIONAL ${ }^{1}$
}

\author{
Nitrogen fertilization of bean at sowing and as topdressing \\ under no-tillage and conventional tillage
}

\author{
Jainir Alves Junior², Messias José Bastos de Andrade ${ }^{3}$, Janice Guedes de Carvalho ${ }^{4}$, \\ Neiva Maria Batista Vieira ${ }^{5}$, Augusto Ramalho de Morais ${ }^{6}$
}

\begin{abstract}
RESUMO
Com o objetivo de avaliar, a campo, a resposta do feijoeiro a doses de nitrogênio por ocasião da semeadura e em cobertura, foram conduzidos dois experimentos (plantio direto e convencional), na safra das águas 2004/05. O delineamento estatístico foi em blocos casualizados com três repetições e esquema fatorial $4 x 4$, envolvendo 4 doses de $\mathrm{N}$ no plantio $\left(0,40,80\right.$ e $120 \mathrm{~kg}$.ha- $\left.{ }^{-1}\right)$ e 4 doses de $\mathrm{N}$ em cobertura $\left(0,40,80\right.$ e $\left.120 \mathrm{~kg} \cdot \mathrm{ha}^{-1}\right)$, aos 20 DAE. Cada parcela foi constituída por quatro linhas de $5 \mathrm{~m}$ de comprimento, espaçamento de $0,5 \mathrm{~m}$ e densidade de 16 sementes. $\mathrm{m}^{-1}$. Foram avaliados os estandes inicial e final e o rendimento de grãos. Em ambos os sistemas de plantio, o incremento do fertilizante nitrogenado de plantio reduziu o estande de plantas. De maneira geral, no plantio direto, a resposta à aplicação de $\mathrm{N}$ no plantio foi quadrática e a dose correspondente à máxima produtividade variou com as doses de cobertura. No plantio convencional, essa resposta foi linear decrescente, em razão do maior efeito de $\mathrm{N}$ de plantio sobre o estande. A resposta à aplicação de $\mathrm{N}$ em cobertura foi quadrática, em ambos os sistemas de plantio e as maiores respostas do rendimento de grãos foram observadas com o emprego da dose de $40 \mathrm{~kg} \cdot \mathrm{ha}^{-1}$ de $\mathrm{N}$ no plantio.
\end{abstract}

Termos para indexação: Nitrogênio, Phaseolus vulgaris, sistemas de plantio.

\section{ABSTRACT}

With the aim of evaluating the responses of bean to nitrogen fertilization rates at sowing and topdressing in the field, two experiments were carried out (no-tillage and conventional tillage), in the rainy season 2004/2005. The experimental design was in randomized blocks with three replicates in a $4 \times 4$ factorial structure encompassing four $\mathrm{N}$ rates at sowing $\left(0,40,80\right.$, and $\left.120 \mathrm{~kg} . \mathrm{ha}^{-1}\right)$ and four topdressing $\mathrm{N}$ rates $\left(0,40,80\right.$, and $\left.120 \mathrm{~kg} \cdot \mathrm{ha}^{-1}\right)$ at 20 DAE. Each plot was composed of four 5 -m-long rows, $0.5 \mathrm{~m}$ apart from each other and a 16 seed. $\mathrm{m}^{-1}$ density was used. Initial and final stand and grain yield were assessed. In both crop management systems, the increasing nitrogen fertilization rate at sowing reduced the plant stand. In general, in no-tillage the response to $\mathrm{N}$ application at sowing was squared and the rate corresponding to maximum yield varied depending on the topdressing rates. In conventional tillage this response decreased linearly, as a function of the higher effect of $\mathrm{N}$ at sowing on final stand. The response to $\mathrm{N}$ topdressing application was squared in both crop management systems and higher responses to grain yield were observed with $40 \mathrm{~kg} \cdot \mathrm{ha}^{-1} \mathrm{~N}$ rate at sowing.

Index terms: Nitrogen, Phaseolus vulgaris, crop management systems.

(Recebido em 21 de maio de 2007 e aprovado em 24 de abril de 2008)

\section{INTRODUÇÃO}

De maneira geral, as recomendações oficiais de adubação nitrogenada preconizam a aplicação de apenas uma fração da dose total no plantio, deixando o restante para aplicação em cobertura. Segundo Malavolta (1980), essa recomendação se deve à baixa exigência inicial de $\mathrm{N}$ pelas culturas anuais, ao efeito salino desse fertilizante sobre a semente e à possibilidade de perdas por lixiviação.
No entanto, este último argumento tem a sua importância reduzida, em função de resultados como o de Urquiaga et al. (1984), os quais demostraram que, ao final da cultura do feijoeiro, $86 \%$ do $\mathrm{N}$ do fertilizante (fonte sulfato de amônio) ainda encontrava-se até os $45 \mathrm{~cm}$ de profundidade, em terra roxa estruturada.

Deve ser mencionado, porém, que no sistema de plantio direto a palhada altera o microclima e influencia

${ }^{1}$ Parte da dissertação do primeiro autor, apresentada à UFLA, para obtenção do Título de Mestre - Trabalho Financiado pela FAPEMIG e CNPq. 'Engenheiro Agrônomo, Mestre - Atual Empresarial - Rua Grão Mongol, 1327, apto. 501 - Sion - 30315-600 - Belo Horizonte, MG jainir@atualempresarial.com.br

${ }^{3}$ Engenheiro Agrônomo, Doutor, Professor Associado - Departamento de Agricultura/DAG - Universidade Federal de Lavras/UFLA - Cx. P. 3037 37200-000 - Lavras, MG - mandrade@ufla.br - Bolsista CNPq

${ }^{4}$ Engenheira Agrônoma, Doutora, Professora Titular - Departamento de Ciência do Solo/DCS - Universidade Federal de Lavras/UFLA - Cx. P. 3037 37200-000 - Lavras, MG - janicegc@ufla.br - Bolsista CNPq

${ }^{5}$ Engenheira Agrônoma, Doutora, Professora - Departamento de Ciências Exatas e Tecnológicas - Universidade Estadual de Montes Claros/UNIMONTES Avenida Reinaldo Viana, 2630 - Bico da Pedra - Cx. P. 91 - 39440-000 - Janaúba, MG - neiva.vieira@unimontes.br

${ }^{6}$ Engenheiro Agrônomo, Doutor, Professor Associado - Departamento de Ciência Exatas/DEX - Universidade Federal de Lavras/UFLA - Cx. P. 3037 37200-000 - Lavras, MG - amorais@ufla.br - Bolsista CNPq 
diretamente os processos biológicos (Cornélio et al., 2007), diferenciando-os bastante daqueles que ocorrem no sistema convencional de plantio.

Com relação ao parcelamento, Urben Filho et al. (1980), estudando doses $\left(0,40,80,120\right.$ e $\left.160 \mathrm{~kg} \mathrm{ha}^{-1}\right)$ e modos de aplicação (aplicados totalmente em cobertura, todo no plantio ou $1 / 3$ no plantio e $2 / 3$ em cobertura), não encontraram diferenças de produtividade entre os modos de aplicação, embora doses maiores de $\mathrm{N}$ aplicadas no plantio tenham influenciado negativamente no estande final. Já Araya et al. (1981) observaram resposta positiva do rendimento de grãos, parcelando $1 / 2$ no plantio e $1 / 2$ em cobertura no período de 15 a 29 DAE. Araújo et al. (1994), estudando a época de aplicação do N em cobertura, concluíram ser vantajosa a aplicação parcelada e recomendaram a cobertura até aos 30 DAE. Khiel et al. (1993), estudando o efeito de doses e modos de aplicação de uréia na produção do feijoeiro, observaram que a aplicação de uma só vez em cobertura conferiu as menores produções, enquanto que o fracionamento da dose em duas aplicações (no plantio e cobertura), bem como uma única aplicação no plantio, foram os métodos efetivos. Nesse estudo, em Latossolo Vermelho Amarelo, a resposta máxima ocorreu com a dose de $66 \mathrm{~kg} \mathrm{ha}^{-1}$, enquanto, em Planossolo solódico, o rendimento aumentou até a dose máxima utilizada $\left(90 \mathrm{~kg} \mathrm{ha}^{-1}\right)$.

Teixeira et al. (2000), trabalhando com doses de até $150 \mathrm{~kg} \mathrm{ha}^{-1}$ de N, $100 \mathrm{~kg} \mathrm{ha}^{-1}$ de $\mathrm{N}$ na semeadura $+50 \mathrm{~kg} \mathrm{ha}^{-1} \mathrm{de}$ $\mathrm{N}$ em cobertura, verificaram resposta linear da cv. Pérola na safra das águas, seca e inverno-primavera, no município de Lavras, MG. No ano seguinte, com as cultivares Carioca e Pérola, Rodrigues et al. (2002), testando doses de até $120 \mathrm{~kg}$ ha $^{-1}$ de $\mathrm{N}$, sendo $80 \mathrm{~kg} \mathrm{ha}^{-1}$ de $\mathrm{N}$ na semeadura $+40 \mathrm{~kg} \mathrm{ha}^{-1}$ de $\mathrm{N}$ em cobertura, na presença de diferentes doses de $\mathrm{P}_{2} \mathrm{O}_{5}$, obtiveram resposta linear em duas safras e quadrática em outra, esta com máxima produtividade estimada com o uso de $108,6 \mathrm{~kg} \mathrm{ha}^{-1}$ de $\mathrm{N}\left(72,4 \mathrm{~kg} \mathrm{ha}^{-1}\right.$ na semeadura e $36,2 \mathrm{~kg} \mathrm{ha}^{-1} \mathrm{em}$ cobertura). Estes resultados, principalmente as respostas lineares, podem possibilitar resposta a doses superiores a 80-100 kg ha ${ }^{-1}$ na semeadura.

Santos et al. (2003), estudando os efeitos do parcelamento de N no feijoeiro, cvs. Rudá e Pérola, cultivadas em várzeas $\left(0,40,80,120\right.$ e 160 kg.ha- ${ }^{-1}$ de N: 1 dose total no plantio; $2-1 / 2$ na semeadura e $1 / 2$ incorporado aos 20 DAE e 3- 1/2 na semeadura e 1/2 aos 20 DAE à lanço) concluíram que, aplicação de parte do $\mathrm{N}$ em semeadura e parte incorporada, foi a mais eficaz.

Conduziu-se este estudo, com o objetivo de avaliar a resposta do feijoeiro a doses de nitrogênio por ocasião da semeadura e em cobertura, em sistema convencional e plantio direto, de forma a fornecer subsídios para recomendação de adubação mais racional e eficiente da cultura.

\section{MATERIAL E MÉTODOS}

O estudo constou de dois experimentos de campo, conduzidos em propriedade particular no município de São Vicente de Minas, em um Latossolo Vermelho Amarelo ácrico (EMBRAPA, 1999), na safra das águas 2004/2005. O primeiro deles foi instalado sob plantio direto e o outro sob sistema de plantio convencional.

Os valores resultantes da análise química de amostras de material dos solos, coletadas à profundidade de 0 a $20 \mathrm{~cm}$, antes da semeadura do feijão, são apresentados na Tabela 1 .

Tabela 1 - Análise química dos solos utilizados (0 a $20 \mathrm{~cm}$ ). UFLA, Lavras, MG, 2007.

\begin{tabular}{|c|c|c|}
\hline Características & Plantio direto & $\begin{array}{c}\text { Plantio } \\
\text { convencional }\end{array}$ \\
\hline $\mathrm{pH}$ em $\mathrm{H}_{2} \mathrm{O}(1: 2,5)$ & $5,9 \mathrm{AcM}$ & $5,5 \mathrm{AcM}$ \\
\hline $\mathrm{P} \mathrm{mg} \mathrm{dm}{ }^{-3(1)}$ & $1,4 \mathrm{MBa}$ & $0,6 \mathrm{MBa}$ \\
\hline $\mathrm{K} \mathrm{mg} \mathrm{dm}{ }^{-3(1)}$ & $27,0 \mathrm{Ba}$ & $23,0 \mathrm{Ba}$ \\
\hline Ca cmolc dm ${ }^{-3(2)}$ & 2,3 M & $0,8 \mathrm{Ba}$ \\
\hline Mg cmolc dm ${ }^{-3(2)}$ & $0,7 \mathrm{M}$ & $0,2 \mathrm{Ba}$ \\
\hline $\mathrm{Al} \mathrm{cmolc} \mathrm{dm}^{-3(2)}$ & $0,0 \mathrm{MBa}$ & $0,0 \mathrm{MBa}$ \\
\hline $\mathrm{S} \mathrm{mg} \mathrm{dm}{ }^{-3(3)}$ & $8,9 \mathrm{MB}$ & $4,5 \mathrm{M}$ \\
\hline M. O. dag kg- ${ }^{1(4)}$ & $1,5 \mathrm{Ba}$ & $1,6 \mathrm{Ba}$ \\
\hline $\mathrm{Zn} \mathrm{mg} \mathrm{dm}{ }^{-3(1)}$ & $1,0 \mathrm{M}$ & $0,6 \mathrm{Ba}$ \\
\hline Fe $\mathrm{mg} \mathrm{dm}^{-3(1)}$ & $34,6 \mathrm{~B}$ & $36,6 \mathrm{~B}$ \\
\hline Mn $\mathrm{mg} \mathrm{dm}^{-3(1)}$ & $3,8 \mathrm{Ba}$ & $3,5 \mathrm{Ba}$ \\
\hline $\mathrm{Cu} \mathrm{mg} \mathrm{dm} \mathrm{m}^{-3(1)}$ & 7,7 A & $3,0 \mathrm{~A}$ \\
\hline $\mathrm{B} \mathrm{mg} \mathrm{dm} \mathrm{m}^{-3(5)}$ & $0,2 \mathrm{Ba}$ & $7,7 \mathrm{~A}$ \\
\hline
\end{tabular}

* Análises realizadas pelo Laboratório de Fertilidade do Solo do Departamento de Ciência do Solo da UFLA e interpretação de acordo com a Comissão de Fertilidade do Solo do Estado de Minas Gerais, 5a. aproximação (RIBEIRO et al., 1999). (1) Extrator Mehlich, ${ }^{(2)}$ Extrator $\mathrm{KCl} 1 \mathrm{~N},{ }^{(3)}$ Extrator fosfato monocálcico em ácido acético, (4) Oxidação: $\mathrm{Na}_{2} \mathrm{Cr}_{2} \mathrm{O}_{7}$ $4 \mathrm{~N}+\mathrm{H}_{2} \mathrm{SO}_{4} 10 \mathrm{~N},{ }^{(5)}$ Extrator água quente, $\mathrm{AcM}=$ acidez média, $\mathrm{MBa}=$ muito baixo, $\mathrm{Ba}=$ baixo, $\mathrm{M}=$ médio, $\mathrm{B}=$ bom, $\mathrm{MB}=$ muito bom, $\mathrm{A}=$ alto.

Foi utilizada a cultivar BRS-MG Talismã. Apresenta grãos tipo carioca, crescimento indeterminado com guias longas (tipo III), porte prostrado, ciclo médio de 85 dias, resistência o mosaico-comum (VMCF) e a várias raças de antracnose (Colletotrichum lindemuthianum), manchaangular (Phaeoisariopsis griseola) e ferrugem (Uromyces appendiculatus) (MATOS et al., 2007).

Em plantio convencional, o preparo de solo constou de uma aração e uma gradagem, usualmente realizadas na propriedade. No plantio direto, os ensaios foram instalados 
sob palhada de milho, dessecada quinze dias antes do plantio, com 2,5 kg de Roundup WG® por hectare. Não foi realizada a correção do solo.

O delineamento estatístico utilizado em cada experimento foi blocos casualizados, com três repetições e esquema fatorial $4 \times 4$, envolvendo quatro doses de $\mathrm{N}$ aplicadas na semeadura $\left(0,40,80\right.$ e $120 \mathrm{~kg} \mathrm{ha}^{-1}$ de $\mathrm{N}$, fonte uréia) e quatro doses de $\mathrm{N}$ aplicados em cobertura incorporada $\left(0,40,80\right.$ e $120 \mathrm{~kg} \mathrm{ha}^{-1} \mathrm{de} \mathrm{N}$, fonte uréia), aos 20 dias após emergência (DAE).

Todas as parcelas receberam idêntica adubação fosfatada e potássica, determinada pelos resultados de análise de solo e da interpretação segundo Chagas et al. (1999) (Tabela 1).

Em ambos os experimentos, a semeadura foi manual, adotando-se a densidade de 16 sementes por metro e parcelas de quatro linhas de $5 \mathrm{~m}$ de comprimento, com espaçamento de $0,5 \mathrm{~m}$, sendo a área útil constituída pelas duas linhas centrais.

Os tratos culturais foram os normalmente dispensados à cultura na região e os experimentos não receberam irrigação. Em cada experimento, foi avaliado o estande inicial e final, além do rendimento de grãos.

Os dados foram submetidos às análises de variância individual e conjunta, e os efeitos das doses de $\mathrm{N}$ estudadas por meio de análise de regressão. A comparação entre as médias obtidas em plantio direto e convencional foi feita pelo teste de Scott-Knott (FERREIRA, 2000).

\section{RESULTADOS E DISCUSSÃO}

A análise de variância conjunta dos dados apresentou efeito significativo de adubação nitrogenada de plantio $(\mathrm{P})$ e da interação $\mathrm{P}$ x sistemas de plantio $(\mathrm{S})$ sobre todas as características avaliadas. $\mathrm{O}$ estande inicial foi influenciado, ainda, pela interação $\mathrm{P}$ x adubação de cobertura (C). O rendimento de grãos foi influenciado por todas as fontes de variação, inclusive interações. Houve boa precisão experimental.

Nas doses mais baixas de $\mathrm{N}$ no plantio (0 e 40 $\left.\mathrm{kg} \cdot \mathrm{ha}^{-1}\right)$ não foram encontradas diferenças significativas de estande inicial entre os sistemas de plantio e as populações resultantes destes tratamentos situaram-se dentro das recomendações (DEL PELOSO, 1996; EMBRAPA, 1982). Entretanto, em doses mais altas (80 e $120 \mathrm{~kg} \cdot \mathrm{ha}^{-1}$ de N), observa-se que houve maior estande no plantio direto (Figura 1), mostrando que, nesse sistema, o efeito salino do fertilizante sobre a germinação das sementes foi amenizado. A maior umidade, maior imobilização do N no plantio direto (ARF et al., 2004; STONE \& MOREIRA, 2000) e maior teor de matéria orgânica podem ter amenizado o efeito provocado pelo fertilizante.

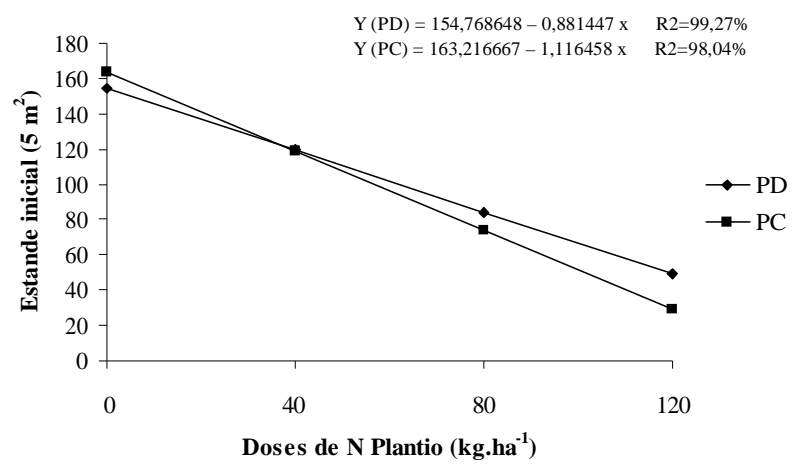

Figura 1 - Estande inicial $\left(5 \mathrm{~m}^{2}\right)$ do feijoeiro cv. Talismã, em função de doses de N no plantio e sistemas de plantio, São Vicente de Minas, águas 2004/05. UFLA, Lavras, MG, 2007.

$\mathrm{O}$ aumento das doses de $\mathrm{N}$ diminui o estande inicial, em ambos os sistemas de plantio, de forma linear (Figuras 1 e 2). Nota-se, também, que, no sistema de plantio direto, essa queda é menos acentuada com relação ao plantio convencional. No plantio direto, para cada kg.ha-1 de $\mathrm{N}$ aplicado, foi observada uma queda de quase 0,9 plantas por parcela, redução equivalente a cerca de 1.760 plantas.ha ${ }^{-1} \mathrm{e}$, no convencional essa queda representou pouco mais de 1,1 planta por parcela, ou seja, cerca de 2.230 plantas.ha $^{-1}$ (Figura 1).

O mesmo efeito se observa em função da interação doses de N no plantio x N em cobertura (Figura 2). Em todas as doses de $\mathrm{N}$ em cobertura houve queda acentuada do número de plantas por parcela, com o incremento da dose de plantio, registrando-se a mesma variação, de 0,9 (com $120 \mathrm{~kg} \mathrm{ha}^{-1}$ de N ) a 1,1 planta (com $80 \mathrm{~kg} \mathrm{ha}^{-1}$ de N) por parcela. Mais uma vez, pode ser constatado o efeito salino do fertilizante nitrogenado já relatado por Silveira \& Damasceno (1993) e que aqui se manifestou independente da dose de cobertura utilizada.

Esses resultados não deixam dúvidas, portanto, sobre o efeito negativo do aumento da dose de $\mathrm{N}$ em semeadura sobre o estande inicial e que, de acordo com vários autores, é consequiência do efeito salino do fertilizante sobre a germinação das sementes (KIKUTI et al., 2005; RODRIGUES et al., 2002; SILVEIRA \& DAMASCENO, 1993; TEIXEIRA et al., 2000). Observa-se, ainda, que, embora se trate de semeadura das águas, as chuvas ocorridas durante o estabelecimento da cultura não foram suficientes para amenizar esse efeito. 
Ao contrário do estande inicial, o estande final não diferiu entre os sistemas nas doses mais altas de $\mathrm{N}$ no plantio (80 e 120 kg.ha-1 de N); entretanto, nas doses mais baixas (0 e $\left.40 \mathrm{~kg} \cdot \mathrm{ha}^{-1}\right)$, houve um maior número de plantas no plantio convencional (Figura 3 ).

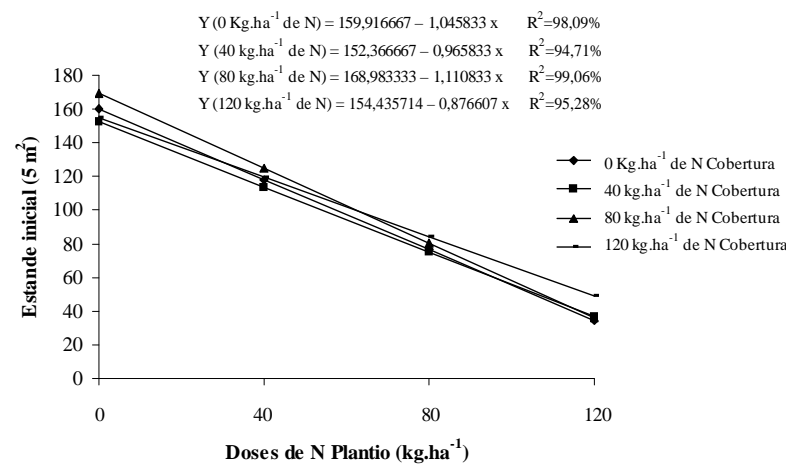

Figura 2 -Estande inicial $\left(5 \mathrm{~m}^{2}\right)$ do feijoeiro cv. Talismã, em função de doses de N no plantio e cobertura, São Vicente de Minas, águas 2004/05. UFLA, Lavras, MG, 2007.

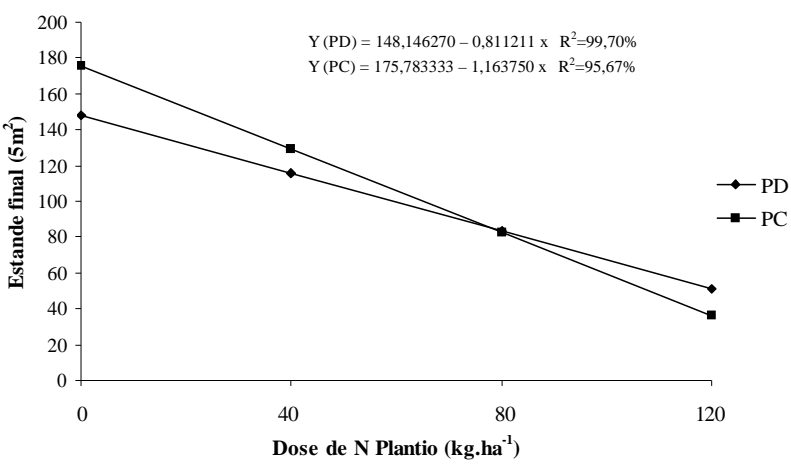

Figura 3 - Estande final $\left(5 \mathrm{~m}^{2}\right)$ do feijoeiro cv. Talismã, em função de doses de $\mathrm{N}$ no plantio e sistemas de plantio, São Vicente de Minas, águas 2004/05. UFLA, Lavras, MG, 2007.

Seguindo o mesmo comportamento do estande inicial, à medida que se aumentaram as doses de $\mathrm{N}$ no plantio, observou-se uma diminuição do estande final, tendo essa queda sido mais acentuada no plantio convencional (Figura 3). Esta redução resultou do efeito sobre o estande inicial e também foi encontrada por outros autores, como Rodrigues et al. (2002). Por outro lado, a proximidade dos valores de estande inicial e final significa que houve alta sobrevivência das plantas durante o ciclo da cultura.
De maneira geral, em todas as doses de $\mathrm{N}$ no plantio, os maiores rendimentos foram obtidos no sistema de plantio direto (Tabela 2), o que pode estar relacionado também à maior fertilidade do solo (Tabela 1). Além disso, a maior presença de alguns nutrientes, como $\mathrm{N}$ e $\mathrm{K}$, na palhada e a absorção de $\mathrm{P}$, favorecida pela maior umidade no plantio direto (STONE \& MOREIRA, 2000; VIEIRA, 2006), podem ter contribuído para o maior rendimento de grãos.

Tabela 2 - Rendimento de grãos $\left(\mathrm{kg} \cdot \mathrm{ha}^{-1}\right)$ do feijoeiro cv. BRS-MG Talismã, em São Vicente de Minas, águas 2004/ 2005, em função de sistemas de plantio e doses de $\mathrm{N}$ em plantio e cobertura. UFLA, Lavras, 2007.

\begin{tabular}{ccc}
\hline Tratamentos & & Média \\
\hline \multirow{3}{*}{ N Plantio } & 0 & 1376 \\
& 40 & 1524 \\
& 80 & 1219 \\
& 120 & 971 \\
\hline \multirow{2}{*}{ N Cobertura } & 0 & 1125 \\
& 40 & 1126 \\
& 80 & 1523 \\
Sistema de plantio & 120 & 1217 \\
\hline CV $(\%)$ & PD & 1939 \\
\hline
\end{tabular}

$\mathrm{O}$ efeito da interação doses de $\mathrm{N}$ no plantio $\mathrm{x}$ cobertura sobre o rendimento de grãos, em plantio direto, pode ser observado na Figura 4. Nas doses de 80 e 120 kg.ha ${ }^{-1}$ de $\mathrm{N}$ em cobertura as maiores produtividades $(2.418$ e $2.469 \mathrm{~kg} \cdot \mathrm{ha}^{-1}$ ) foram obtidas com doses de plantio bastante semelhantes (49 e $50 \mathrm{~kg} \cdot \mathrm{ha}^{-1}$ de $\mathrm{N}$, respectivamente). Já nas parcelas nas quais não se aplicou $\mathrm{N}$ em cobertura, o maior rendimento $\left(1.861 \mathrm{~kg} \cdot \mathrm{ha}^{-1}\right)$ foi obtido com $79 \mathrm{~kg} \cdot \mathrm{ha}^{-1}$ de $\mathrm{N}$ em plantio, resultado próximo ao de Valério (2002), quando isolou o efeito das doses de $\mathrm{N}$ no plantio na cv Pérola. $\mathrm{Na}$ dose de $40 \mathrm{~kg} \cdot \mathrm{ha}^{-1}$ de $\mathrm{N}$ em cobertura, houve resposta linear, com queda acentuada da produtividade à medida que se aumentaram as doses de $\mathrm{N}$ em plantio. Essa resposta linear permitiu prever um decréscimo de, aproximadamente, 8,7 kg.ha-1 de grãos para cada $\mathrm{kg}$ de $\mathrm{N}$ aplicado em plantio. Este efeito, entretanto, foi discrepante do encontrado nas demais doses de $\mathrm{N}$ em cobertura e deve ser analisado com cautela.

Em plantio convencional, apenas na presença de 0 e $80 \mathrm{~kg} \cdot \mathrm{ha}^{-1}$ de $\mathrm{N}$ em cobertura houve efeito significativo das doses de $\mathrm{N}$ no plantio (Figura 5). Esse comportamento, 


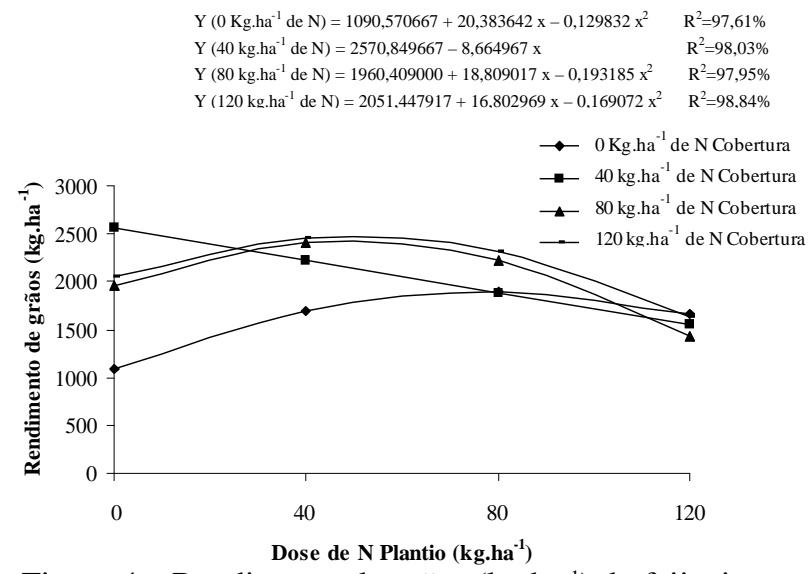

Figura 4 - Rendimento de grãos (kg.ha $\left.{ }^{-1}\right)$ do feijoeiro cv. Talismã, em função de doses de $\mathrm{N}$ no plantio e cobertura, São Vicente de Minas, águas 2004/05, plantio direto. UFLA, Lavras, MG, 2007.

certamente resultante do efeito verificado sobre o estande, foi linear nas duas situações, com quedas de produtividade de 9,3 a 10,4 kg.ha-1 de grãos para cada kg de $\mathrm{N}$ no plantio.

No plantio direto, portanto, houve pontos de máxima produtividade (Figura 4), fato não observado em plantio convencional, que apresentou efeito linear decrescente (Figura 5). A maior umidade no plantio direto pode ter amenizado o efeito salino do fertilizante, associado à maior quantidade de nutrientes na palhada, como $\mathrm{N}$ e $\mathrm{K}$, facilitando o arranque inicial da cultura, promovendo maior sobrevivência de plantas e, conseqüentemente, maiores produtividades. Segundo Rosolem (1996), condições de resposta ao $\mathrm{N}$ estão relacionadas com solo do local de semeadura, cultura anterior e teor de matéria orgânica, dentre outros fatores.

No plantio direto, em todas as doses de plantio houve efeito significativo da cobertura (Figura 6), entretanto, na dose de $120 \mathrm{~kg} \cdot \mathrm{ha}^{-1}$ de $\mathrm{N}$ no plantio, esse efeito foi menor, apresentando uma produtividade média de 1.217 kg.ha- ${ }^{-1}$ de grãos. Nas doses 0 e 40 kg.ha ${ }^{-1}$ de N no plantio, houve efeito quadrático das doses em cobertura, com resultados bastante semelhantes, principalmente no que diz respeito à produtividade máxima alcançada (2.404 e $2.435 \mathrm{~kg} \cdot \mathrm{ha}^{-1}$ ).

As doses de $\mathrm{N}$ em cobertura correspondentes, $73 \mathrm{e}$ 101 kg.ha-1, mostraram-se bastante inferiores às encontradas por Meira et al. (2005), também em plantio direto, mas com produtividades superiores às do presente trabalho. Na dose de $80 \mathrm{~kg} \cdot \mathrm{ha}^{-1}$ de $\mathrm{N}$ no plantio houve comportamento linear das doses de cobertura, com elevação da produtividade à medida que se aumentou as doses de $\mathrm{N}$ em cobertura. Para cada kg de $\mathrm{N}$ aplicado em cobertura

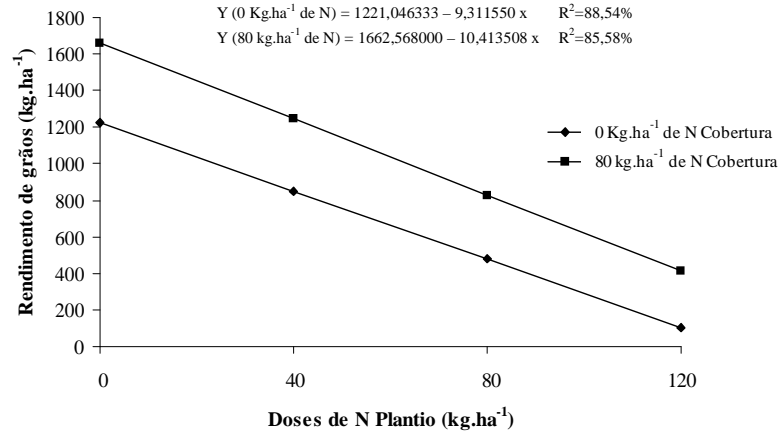

Figura 5 - Rendimento de grãos $\left(\mathrm{kg} \cdot \mathrm{ha}^{-1}\right)$ do feijoeiro cv. Talismã, em função de doses de N no plantio e cobertura, São Vicente de Minas, águas 2004/05, plantio convencional. UFLA, Lavras, MG, 2007.

houve um aumento de 5,0 kg.ha- ${ }^{-1}$ de grãos, bastante semelhante ao encontrado por Buzetti et al. (1992) com a cv. Carioca.

Em plantio convencional, não houve efeito significativo da cobertura na ausência de aplicação de $\mathrm{N}$ em plantio (Figura 7). Nas demais doses de plantio houve comportamento quadrático, tendo, na presença de $40 \mathrm{ou}$ $120 \mathrm{~kg} \cdot \mathrm{ha}^{-1}$ de $\mathrm{N}$ em plantio, a máxima produtividade sido alcançada com doses bastante semelhantes (48 e 60 kg.ha-1 de $\mathrm{N}$ em cobertura, respectivamente).

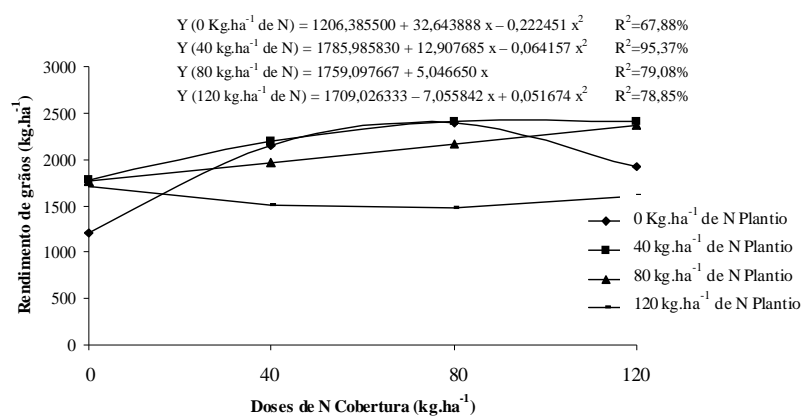

Figura 6 - Rendimento de grãos $\left(\mathrm{kg} \cdot \mathrm{ha}^{-1}\right)$ do feijoeiro cv. Talismã, em função de doses de $\mathrm{N}$ no plantio e cobertura, São Vicente de Minas, águas 2004/05, plantio direto. UFLA, Lavras, MG, 2007.

Na dose $40 \mathrm{~kg}$ de $\mathrm{N}$ no plantio, o maior rendimento foi cerca de duas vezes maior que o alcançado com 120 $\mathrm{kg} . \mathrm{ha}^{-1}$, o que pode ser explicado pelo menor estande nesta última dose, resultante do efeito salino do fertilizante nitrogenado sobre a germinação das sementes. A dose de $80 \mathrm{~kg} \cdot \mathrm{ha}^{-1}$ de $\mathrm{N}$ no plantio teve comportamento diferenciado das demais, com aumento do rendimento nas maiores doses de cobertura. De acordo com estes últimos resultados, a dose de $40 \mathrm{~kg} \cdot \mathrm{ha}^{-1}$ de $\mathrm{N}$ no plantio, associada 
a $48 \mathrm{~kg} \cdot \mathrm{ha}^{-1}$ de $\mathrm{N}$ em cobertura, teria proporcionado os melhores resultados (Figura 7), com menor dose total de adubo nitrogenado.

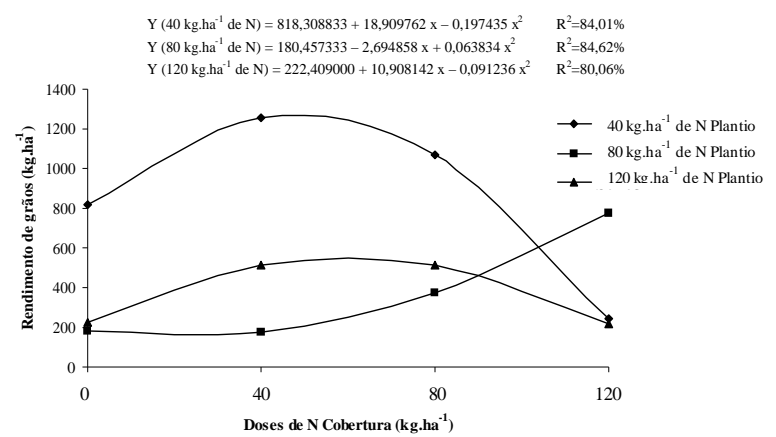

Figura 7 - Rendimento de grãos $\left(\mathrm{kg} \cdot \mathrm{ha}^{-1}\right)$ do feijoeiro cv. Talismã, em função de doses de $\mathrm{N}$ no plantio e cobertura, São Vicente de Minas, águas 2004/05, plantio convencional. UFLA, Lavras, MG, 2007.

\section{CONCLUSÕES}

Em ambos os sistemas de plantio, o incremento do fertilizante nitrogenado de plantio reduziu o estande de plantas.

Em geral, no plantio direto, a resposta à aplicação de $\mathrm{N}$ no plantio foi quadrática e a dose correspondente à máxima produtividade variou com as doses de cobertura. No plantio convencional, essa resposta foi linear decrescente, em razão do maior efeito do $\mathrm{N}$ em plantio sobre o estande.

A resposta à aplicação de $\mathrm{N}$ em cobertura foi quadrática, em ambos os sistemas de plantio e as maiores respostas do rendimento de grãos foram observadas com o emprego da dose de $40 \mathrm{~kg} \cdot \mathrm{ha}^{-1}$ de $\mathrm{N}$ no plantio.

\section{REFERÊNCIAS BIBLIOGRÁFICAS}

ARAÚJO, G. A. A.; VIEIRA, C.; MIRANDA, G. V. Efeito da época de aplicação do adubo nitrogenado em cobertura sobre o rendimento do feijão no período de outono-inverno. Revista Ceres, Viçosa, v. 41, n. 236, p. 442-450, jul./ago. 1994.

ARAYA, V. R.; VIEIRA, C.; MONTEIRO, A. A. T.; CARDOSO, A. A.; BRUNE, W. Adubação nitrogenada da cultura do feijão (Phaseolus vulgaris L.) na Zona da Mata de Minas Gerais. Revista Ceres, Viçosa, v. 28, p. 134-149, 1981.

ARF, O.; RODRIGUES, R. A. F.; SÁ, M. E.; BUZETTI, S.; NASCIMENTO, V. Manejo do solo, água e nitrogênio no cultivo de feijão. Pesquisa Agropecuária Brasileira, Brasília, v. 39, n. 2, p. 131-138, fev. 2004.

BUZETTI, S.; ROMEIRO, P. J. M.; ARF, O.; SÁ, M. E.; GUERREIRO NETO, G. Efeito da adubação nitrogenada em componentes da produção do feijoeiro (Phaseolus vulgaris L.) cultivado em diferentes densidades. Cultura Agronômica, v. 1, p. 11-19, 1992.

CHAGAS, J. M.; BRAGA, J. M.; VIEIRA, C.; SALGADO, L. T.; JUNQUEIRA NETO, A.; ARAÚJO, G. A. A.; ANDRADE, M. J. B.; LANA, R. M. Q.; RIBEIRO, A. C. Feijão. In: RIBEIRO, A. C.; GUIMARÃES, P. T. G.; ALVAREZ, V. H.

Recomendações para o uso de corretivos e fertilizantes em Minas Gerais: $5^{\text {a }}$ aproximação. Viçosa: CFSEMG, 1999. p. 306-309.

CORNÉLIO, V. M. O.; REIS, M.S.; SOARES, A. A.; SOARES, P. C.; OLIVEIRA, J. A. Efeito de doses e épocas da aplicação de nitrogênio na incidência de doenças, produção e qualidade sanitária das sementes de arroz. Ciência e Agrotecnologia, Lavras, v. 31, n. 1, p. 47-52, jan./fev., 2007

DEL PELOSO, M. J. Cultivo irrigado em terras altas. In: ARAÚJO, R. S. et al. Cultura do feijoeiro comum no Brasil. Piracicaba: Potafós, 1996. p. 517-584.

EMPRESA BRASILEIRA DE PESQUISA AGROPECUÁRIA. Sistema brasileiro de classificação de solos. Brasília, DF, 1999. 412 p.

\section{EMPRESA BRASILEIRA DE PESQUISA}

AGROPECUÁRIA. Centro Nacional de Pesquisa de Arroz e Feijão. Recomendações técnicas para a cultura de feijão com irrigação suplementar. Goiânia, 1982. 21 p. (Circular técnica, 12).

FERREIRA, D. F. Análises estatísticas por meio do Sisvar para Windows versão 4.0. In: REUNIÃO ANUAL DA REGIÃO BRASILEIRA DA SOCIEDADE INTERNACIONAL DE BIOMETRIA, 45., 2000, São Carlos. Anais... São Carlos: UFSCar, 2000. p. 255-258.

KHIEL, J. C.; SILVEIRA, R. I.; BRITO NETO, J. Rates and methods of applying urea to common beans. Scientia Agrícola, Piracicaba, v. 50, n. 2, p. 254-260, jun./set. 1993. 
KIKUTI, H.; ANDRADE, M. J. B.; CARVALHO, J. G.; MORAIS, A. R. Nitrogênio e fósforo em feijão (Phaseolus vulgaris L.) variedade cultivada BRS MG Talismã. Acta Scientiarum, Maringá, v. 27, n. 3, p. 415422, July/Sept. 2005.

MATOS, J. W.; RAMALHO, M. A. P.; ABREU, A.F. B. Trinta e dois anos do programa de melhoramento genético do feijoeiro comum em Minas Gerais. Ciência e Agrotecnologia, Lavras, v. 31, n. 6, p. 1749-1754, nov./ dez., 2007.

MALAVOLTA, E. Elementos de nutrição mineral de plantas. São Paulo: Agronômica Ceres, 1980. 251 p.

MEIRA, F. A.; SÁ, M. E.; BUZETTI, S.; ARF, O. Doses e épocas de aplicação de nitrogênio no feijoeiro irrigado cultivado em plantio direto. Pesquisa Agropecuária Brasileira, Brasília, v. 40, n. 4, p. 383-388, abr. 2005.

RIBEIRO, A. C.; GUIMARÃES, P. T. G.; ALVAREZ, V. H. Recomendações para o uso de corretivos e fertilizantes em Minas Gerais: $5^{\text {a }}$ aproximação. Viçosa: CFSEMG, 1999. $356 \mathrm{p}$.

RODRIGUES, J. R. M.; ANDRADE, M. J. B.; CARVALHO, J. G.; MORAIS, A. R.; REZENDE, P. M. População de plantas e rendimento de grãos do feijoeiro em função de doses de nitrogênio e fósforo. Ciência e Agrotecnologia, Lavras, v. 26, n. 6, p. 1218-1227, nov./ dez. 2002.

ROSOLEM, C. A. Calagem e adubação mineral. In: ARAÚJO, R. S.; RAVA, C. A.; STONE, L. F.; ZIMMERMANN, M. J. O. (Eds.). Cultura do feijoeiro comum no Brasil. Piracicaba: Potafós, 1996. p. 353-390.

SANTOS, A. B.; FAGERIA, N. K.; SILVA, O. F.; MELO, M. L. B. Resposta do feijoeiro ao manejo de nitrogênio em várzeas tropicais. Pesquisa Agropecuária Brasileira, Brasília, v. 38, n. 11, p. 1265-1271, 2003.
SILVEIRA, P. M.; DAMASCENO, M. A. Doses e parcelamento de $\mathrm{K}$ e de $\mathrm{N}$ na cultura do feijoeiro irrigado. Pesquisa Agropecuária Brasileira, Brasília, v. 28, n. 11, p. 1269-1276, nov. 1993.

STONE, L. F.; MOREIRA, J. A. A. Efeitos dos sistemas de preparo do solo no uso da água e na produtividade do feijoeiro. Pesquisa Agropecuária Brasileira, Brasília, v. 35, n. 4 , p. 835-841, abr. 2000.

TEIXEIRA, I. R.; ANDRADE, M. J. B.; CARVALHO, J. G.; MORAIS, A. R.; CORREAA, J. B. D. Resposta do feijoeiro (Phaseolus vulgaris L. cv. Pérola) a diferentes densidades de semeadura e doses de nitrogênio.

Ciência e Agrotecnologia, Lavras, v. 24, n. 2, p. 399-408, abr./jun. 2000.

URBEN FILHO, G.; CARDOSO, A. A.; VIEIRA, C.; FONTES, L. A. N.; THIÉBAUT, J. T. L. Doses e modos de aplicação do adubo nitrogenado na cultura do feijão (Phaseolus vulgaris L.). Revista Ceres, Viçosa, v. 27, n. 151, p. 302-312, maio/jun. 1980.

URQUIAGA, C. S.; LIBARDI, P. L.; REICHARDT, K.; MORAES, S. O.; VICTORIA, R. L. Variação do nitrogênio nativo e do proveniente do fertilizante, em terra roxa estruturada, durante o desenvolvimento de uma cultura do feijão. Revista Brasileira de Ciência do Solo, Campinas, v. 8, n. 2, p. 223-227, maio/ago. 1984.

VALÉRIO, C. R. Resposta do feijoeiro comum ao nitrogênio no plantio, em cobertura e em diferentes safras. 2002. Tese (Doutorado em Fitotecnia) Universidade Federal de Lavras, Lavras, 2002.

VIEIRA, N. M. B. Crescimento e Marcha de absorção de nutrientes no feijoeiro cvs. BRS-MG Talismã e Ouro Negro, em plantio direto e convencional. 2006.

Dissertação (Mestrado em Fitotecnia) - Universidade Federal de Lavras, Lavras, 2006. 